\title{
Statistical Research and Efficiency in the Process of Direct-Flow Ginning
}

\author{
A. T. Majidov, N. M. Safarov
}

\begin{abstract}
The present time more attention is allocated with the purpose about an opportunity manufacture qualitative products to improve technologies. In clause, the improvement of engineering and technology for allocation fibrous raw material is investigated. The scientific significance of the research results lies in obtaining dynamic and mathematical models of motion, numerically solving the problems of determining the laws of motion and parameter dependencies, the modes of motion of the recommended working bodies (saw cylinder, working chamber, grate, raw roller accelerator, chain gear for saw cylinder drive, bearing support) saw gin. The practical significance of the research results is to improve the saw gin, which allows obtaining high-quality cotton fiber with high productivity due to the intensification of the ginning process, an increase in the working life, as well as a decrease in the required drive power. The technology and design of a heated gin working chamber for ginning raw cotton of high humidity has been developed.
\end{abstract}

Keywords: Cotton fiber, raw cotton, small-letter, factor, technology, fibrous material, process, fluctuation, fraction, experiments, ginning.

\section{INTRODUCTION}

$A_{n}$ important factor in ensuring the stability of the volume of cotton production and increasing the competitiveness of raw materials in the world market is the production of high-quality cotton fiber. In this direction, research is underway to create a new generation of technologically reliable and highly efficient machines and mechanisms for the primary processing of raw cotton.

In the Republic of Uzbekistan, large-scale measures are being taken to develop highly efficient equipment and technologies for the primary processing of raw cotton, which ensure the receipt of high-quality products. At the same time, it is important to create equipment and technologies that ensure the preservation of the quality and quantity of harvested raw cotton and produced cotton products at

Revised Manuscript Received on February 15, 2020.

* Correspondence Author

Abduvali Turgunpulatovich Majidov, Doctoral Student. Namangan Institute of Engineering and Technology, Namangan, Uzbekistan. Email: niei_info@edu.uz

Nazirjon Muhammdjonovich Safarov, Department of Technical Science, Dots. Namangan Institute of Engineering and Technology. Email: niei_info@edu.uz

(C) The Authors. Published by Blue Eyes Intelligence Engineering and Sciences Publication (BEIESP). This is an open access article under the CC BY-NC-ND license (http://creativecommons.org/licenses/by-nc-nd/4.0/) ginneries, which make it possible to reduce the consumption of raw materials and energy [1-4].

In world practice, special attention is paid to the development of new models of equipment and technology for ginning medium-fiber varieties of raw cotton. At the same time, the implementation of targeted scientific research on the development of highly efficient designs of the working bodies of the main technological machinery of ginneries saw gins, the creation of methods for calculating the parameters and modes of movement that allow a significant increase in ginning productivity at high humidity of the raw cotton with maximum preservation of the natural properties of cotton fiber is considered one of the important tasks were done [5-8].

\section{RESEARCH METHODOLOGY}

It is desirable to emphasize that the new enterprises should be equipped with modern high-tech computer machines that meet the modern requirements. These tasks will need to be solved by highly qualified mechanical engineers.

When analytical expression of the function of straight-through type ginning construction is unknown we may express as the equation of multinomial and regressive of the function.

$$
y=b_{0}+\sum_{i=1}^{k} b_{i} X_{i}+\sum_{i=1}^{k} b_{i i} X_{i}^{2}+\sum_{i<1}^{k} b_{i j} X_{i} X_{j}+\sum_{i<j<l}^{k} b_{i j l} X_{i} X_{j} X_{l}
$$

Here:

$b_{0}=\frac{1}{N} \sum_{u=1}^{N} \bar{y}_{u}, b_{i}=\frac{1}{N} \sum_{u=1}^{N} X_{i u} \bar{y}_{u}, b_{i j}=\frac{1}{N} \sum_{u=1}^{N} X_{i u} X_{j u} \bar{y}_{u}$, $b_{i j k}=\frac{1}{N} \sum_{u=1}^{N} X_{i u} X_{j u} X_{k u} \bar{y}_{u}$

$y$ - the calculated value of the optimization parameter, $x_{1}$ - the independent input parameters, which vary during the experiment $b_{0}, b_{i}, b_{i j}, b_{i j k b}$ - regression coefficients determined from the results of the experiment.

(1) the optimization criterion "y" is chosen to construct the mathematical model in the form of equations; an independent variable is chosen $x_{1}, b_{0}, b_{i}, b_{i j}, b_{i j k b}$ are the regression coefficients, and the response and plan function are defined. [9] To write the experimental plan and process the results of the experiment $x_{1}, x_{2}$ Small-letter, coded values are used $x_{i}$ encoded (dimensionless size) and $x_{i}$. 
The physical (natural) variable is interconnected in the following ratio:

$$
X_{i}=\frac{x_{i}-x_{i 0}}{\Delta i}
$$

Here $\Delta_{u}=\frac{x_{\max }+x_{\min }}{2}$ - interval of variation of natural

value; $x_{i 0}$-is the natural value of zero, $x_{i 0}=\frac{x_{\max }-x_{i \min }}{2}$, $x_{i \max }, x_{i \min }$ - is the natural value of the lower and upper levels of the factor.

Factor coding is equivalent to moving the coordinate head to the level of the key factors (central point of experience) and changing the scale. All encoding factors are dimensionless and normalized sizes. During the experiment, they adopt a value of $-1,0,+1$.
These values are called the level of factors. (1) The coefficients in the estimated multivariate independent variables indicate the degree of influence of the factors. If the coefficient is positive, the output factor increases with the increase of the factor, while the negative factor increases as the factor decreases.

A full factor is called a practice where the levels of possible combination (cumulative) factors are realized. If the " $k$ " factors change in two levels, all possible sets are $\mathrm{N}_{2}=2 \mathrm{k}$. If the " $k$ " factors change to three levels, then $\mathrm{N}_{3}=3 \mathrm{k}$.

We create a regression equation for fractions. We first formulate a two-level $(k=2)$, three-factor experimental plan $\boldsymbol{X}_{1}$, with the first factor being the velocity coding head, the second is the two parallel $\boldsymbol{X}_{2}$ experiments between the coders, the third with the slope of the slope $x_{3}$ in the horizontal plane and the fiber mass [10].

Table 1

The amount of fiber isolated in the first experiment $(p=1) \mathrm{M}(\mathrm{kg})$

\begin{tabular}{|c|c|c|c|c|}
\hline Factors & $x_{\max }$ & $\boldsymbol{X}_{\text {min }}$ & $\Delta$ & $X_{0}$ \\
\hline Speed of rolls. mm / s & 5 & 25 & 10 & 15 \\
\hline Distance between of rolls. mm & 0,05 & 0,025 & 0,01 & 0,015 \\
\hline Angle of deviation on the horizontal plane. degrees & 60 & 40 & 10 & 50 \\
\hline
\end{tabular}

Table 2

In the second experiment $(p=2)$, the amount of separated fiber (M) (kg)

\begin{tabular}{|c|c|c|c|}
\hline Factors & $X_{i \max }$ & $X_{i \min }$ & $\Delta_{i}$ \\
\hline Speed of rolls. mm / s & 5 & 75 & 30 \\
\hline Distance between of rolls. mm & 0,05 & 0,075 & 0 \\
\hline Angle of deviation on the horizontal plane. degrees & 70 & 50 & 0,03 \\
\hline
\end{tabular}

Table 3

In both experiments, the mean value of the fiber isolated was $M$ (kg)

\begin{tabular}{|c|c|c|c|}
\hline Factors & $\vec{X}_{i \max }$ & $\bar{X}_{i \text { min }}$ & $\bar{\Delta}_{i}$ \\
\hline Speed of rolls. mm / s & 5 & 50 & 22,5 \\
\hline Distance between of rolls. mm & 0,5 & 0,05 & 0,225 \\
\hline Angle of deviation on the horizontal plane. degrees & 65 & 45 & 0,275 \\
\hline
\end{tabular}

To determine the regression equation, we construct a matrix of two-level $(k=2)$ three-factor experiments for each function on the responses. Through $\bar{y}_{u i}$, we define the parallel experiments. Thus, $y_{u i}=\frac{1}{n} \sum_{l=1}^{n} y_{0 u l},,(l=1.2 \ldots m)$ was considered in conducting two experiments.

For each variant, we provide the number of sets as corresponding response values for the variation coefficient on the fiber amount $y_{0 u i}$ each of which $n$ is obtained in $\mathrm{m}$

$N_{2}=N=8$ in $m=2$ and enter their values in 4 tables.

Table 4

\begin{tabular}{|c|c|c|c|c|c|c|c|c|c|}
\hline \multirow{2}{*}{ № } & \multicolumn{3}{|c|}{ Range of factors } & \multicolumn{7}{c|}{ Output option (fiber volume) } \\
\cline { 5 - 11 } & \multicolumn{2}{|c|}{$x_{1}$} & $x_{2}$ & $x_{3}$ & $y_{i 1}$ & $y_{i 2}$ & $\bar{y}_{u}$ & $S_{u}^{2}$ & \multicolumn{2}{c|}{$\hat{y}_{u}$} & $R_{0}(\%)$ \\
\hline & - & - & - & 0,300 & 0,310 & 0,305 & 0,00005 & 0,3175 & 4,09 \\
\hline 1 & + & - & - & 0,600 & 0,620 & 0,610 & 0,0002 & 0,5975 & 2,04 \\
\hline 2 & - & + & - & 0,750 & 0,760 & 0,755 & 0,00005 & 0,7675 & 1,65 \\
\hline 3 & &
\end{tabular}




\begin{tabular}{|c|c|c|c|c|c|c|c|c|c|}
\hline 4 & + & + & - & 1,5 & 1,55 & 1,525 & 0,00125 & 1,5125 & 0,81 \\
\hline 5 & - & - & + & 1,25 & 1,40 & 1,375 & 0,01125 & 1,3125 & 0,94 \\
\hline 6 & + & - & + & 1,75 & 1,85 & 1,80 & 0,005 & 1,8125 & 0,69 \\
\hline 7 & - & + & + & 2,0 & 2,15 & 2,1 & 0,005 & 2,0833 & 0,62 \\
\hline 8 & + & + & + & 2,25 & 2,35 & 2,30 & 0,005 & 2,3125 & 0,54 \\
\hline
\end{tabular}

Statistical processing of the experimental results for each response is performed in the following order [11-12]:

1) We investigate the reproduction of parallel experiments in the same category of dispersion $\mathrm{m}$, which characterizes the distribution of their results $S_{u}^{2}$ in the same number.

$$
S_{u}^{2}=\frac{\sum_{p=1}^{2}\left(\bar{y}_{u p}-\bar{y}_{u}\right)^{2}}{m-1}
$$

Here option number of $u-(u=1.2 . . N), p=1.2 .3 . . m$, number of parallel experiments is $m$ - number of parallel experiments $\quad \bar{y}_{u}=\frac{1}{m} \sum_{p=1}^{m} \bar{y}_{u p} \quad-\quad$ average of parallel experiments. We enter the results of $S_{u}^{2}$ values in the table and calculate these statistics for both cases

$$
G=\frac{S_{u(\max )}^{2}}{\sum_{u=1}^{N} S_{u}^{2}}
$$

Here, we calculate the maximum value of the dispersion in the parallel experiments using the formula (3)

$S_{u}^{2}=\left(\bar{y}_{u 1}-\bar{y}_{u}\right)^{2}+\left(\bar{y}_{u 2}-\bar{y}_{u}\right)^{2},(u=1,2,3,4,5,6,7,8)$, $S_{1}^{2}=0.00005, S_{2}^{2}=0.0002, S_{3}^{2}=0.00005, S_{4}^{2}=0.00125$, $S_{5}^{2}=0.01125, S_{6}^{2}=0.005, S_{7}^{2}=0.005, S_{8}^{2}=0.005$

We accept: $S_{u(\max )}^{2}=S_{5}^{2}=0.1125, \sum_{u=1}^{8} S_{u}^{2}=0.0278$ Let's just take statistics as follows:

$$
G=\frac{S_{u(\max )}^{2}}{\sum_{u=1}^{N} S_{u}^{2}}=0.0404
$$

2)We check for the Cochrane criterion,- values are derived from the table data, $\alpha$ significance level $(0<\alpha<1)$, $k_{1}=N, k_{2}=m-1$ - number of degrees of freedom, We consider: $\alpha=0.05, m=3, N=8, G_{\alpha, k_{1}, k_{2}}=G_{0.05,8,3}=0.52$, $G=0.0404$

If the following inequality is observed

$$
G<G_{\alpha, k_{1}, k_{2}}
$$

The Cochrane criterion is appropriate. The uniformity of the variance can be used because all parallel experiments are performed in all variants.

$$
S_{y}^{2}=\frac{1}{N} \sum_{u=1}^{N} S_{u}^{2}=0.003475
$$

That is, this dispersion is used to assess the adequacy of the model. If (5) inequality is not obeyed, the variance on the variants is non-uniform and is not averaged and the following measures should be taken: a) determination of the maximum dispersion of the measurement data in the variant; b) increasing the number of experiments in each option; c) to perform more precise measurement of output parameters.
3) We calculate the regression coefficients by the following formula.

$$
\begin{gathered}
b_{0}=\frac{1}{N} \sum_{u=1}^{N} \bar{y}_{u}, b_{i}=\frac{1}{N} \sum_{u=1}^{N} X_{i u} \bar{y}_{u}, b_{i j}=\frac{1}{N} \sum_{u=1}^{N} X_{i u} X_{j u} \bar{y}_{u}, \\
b_{i j k}=\frac{1}{N} \sum_{u=1}^{N} X_{i u} X_{j u} X_{k u} \bar{y}_{u}
\end{gathered}
$$

After the coefficients are determined, we write the coded variable regression equation.

$y=1.3025+0.25625 x_{1}+0.2925 x_{2}+0.50375 x_{3}+$ $+0.06125 x_{1} x_{2}-0.4875 x_{2} x_{3}-0.055 x_{1} x_{2} x_{3}$

4) We examine the significance of regression coefficients from the Student's criterion.

$$
\Delta b=t_{\alpha, k} \frac{S_{y}}{\sqrt{N}}
$$

$t_{\alpha, k}$ - Student measure, a- level of importance,

$k=N(m-1)$ - Number of degrees of freedom.

If the regression coefficient is higher than the confidence interval, then the coefficients are significant.

$$
\left|b_{0}\right| \geq \Delta b,\left|b_{i}\right| \geq \Delta b,\left|b_{i j}\right| \geq \Delta b,\left|b_{i j k}\right| \geq \Delta b
$$

Let's look at the following $t_{0.05,16}=2.16$, $\Delta b=t_{\alpha, k} \frac{S_{y}}{\sqrt{N}}=0.0450$. According to the above inequality in the regression equation $b_{13}$. The coefficient is considered insignificant, and we write the regression equation without coefficients

$y=1.3025+0.25625 x_{1}+0.2925 x_{2}+0.50375 x_{3}+$ $+0.06125 x_{1} x_{2}-0.4875 x_{2} x_{3}-0.055 x_{1} x_{2} x_{3}$

If the regression equation (8) is accepted, the dispersion of the experiments will be zero. In this case, all regression coefficients $\mathrm{N}=2 \mathrm{k}$ are calculated with the $\mathrm{y}$-values on $\mathrm{N}$, in which case there is no degree of freedom to check the adequacy of the model.

The condition of adequacy is fully managed and the plan of experience is called complete. If there are no significant coefficients in the regression equation (8), the degree of freedom is created and the adequacy of the model should be checked. The adequacy test is to compare the experimental values of the output parameter $\widehat{y}$ with the values calculated by different levels of the input parameters, and to determine their difference in the formula by the procedure.

$$
R_{0}=100\left|\frac{\hat{y}-y}{y}\right|
$$


$\widehat{y}$ and $R_{0}$ The table below shows the values of The linear density of the Fisher criterion is found by the formula for the residual dispersion formula to check the adequacy of the model.

$$
S_{o c}^{2}=\frac{\sum_{u=1}^{8}\left(\widehat{y}_{u}-\bar{y}_{u}\right)^{2}}{N-k-1}=0.000312
$$

Here the value of : indicator in option of $\hat{y}_{u}-\mathrm{N}$, the actual value of the indicator

$\bar{y}_{u}$ - real value of indicator,

$\mathrm{N}$ - number of variants,

$\mathrm{k}$ - the number of factors.

We see the statistics:

$$
F=\frac{S_{o c}^{2}}{S_{y}^{2}}=0.0899
$$

If we examine the Fisher criterion $F_{\alpha, k_{1}, k_{2}}$ by table value here we find looking at the a-valuable surface $k_{1}=N-k-1=4 \quad, \quad k_{2}=N(m-1)=16 \quad$ If this inequality $F<F_{\alpha, k_{1}, k_{2}}$ solved. The adequacy hypothesis is fulfilled.

\section{RESEARCH RESULT}

As $F_{\alpha, k_{1}, k_{2}}=3.01$ Fisher's criterion is appropriate for both cases.

Table 5

$X_{3}=-1\left(x_{3}=45^{0}\right)$

\begin{tabular}{|c|c|c|c|c|c|c|c|c|c|c|c|}
\hline \multirow{2}{*}{$X_{1} / Y_{1}$} & -1 & 0 & -0.6 & -0.4 & -0.2 & 0 & 0.2 & 0.4 & 0.6 & 0.8 & 1 \\
& 0.0025 & 0.0027 & 0.003 & 0.0032 & 0.0035 & 0.0037 & 0.004 & 0.0042 & 0.0045 & 0.0047 & 0.005 \\
\hline \multirow{2}{*}{$0.45 \mathrm{~kg}$} & -0.411 & -0.570 & -0.718 & -0.835 & -0.934 & -1 & & & & & \\
& 0.236 & 0.215 & 0.197 & 0.011 & 0.171 & 0.159 & & & & & \\
\hline \multirow{2}{*}{$0.6 \mathrm{~kg}$} & & 0.025 & -0.165 & -0.326 & -0.464 & -0.582 & -0.686 & -0.777 & -0.858 & -0.930 & 1 \\
& & 0.291 & 0.266 & 0.247 & 0.229 & 0.214 & 0.202 & 0.191 & 0.180 & 0.171 & 0.163 \\
\hline \multirow{2}{*}{$0.8 \mathrm{~kg}$} & 1 & 0.831 & 0.571 & 0.352 & 0.165 & 0 & -0.137 & -0.261 & -0.371 & -0.470 & -0.557 \\
& 0.43 & 0.391 & 0.359 & 0.332 & 0.308 & 0.287 & 0.270 & 0.255 & 0.241 & 0.228 & 0.217 \\
\hline \multirow{2}{*}{$1 \mathrm{~kg}$} & & & & & 1 & 0.794 & 0.589 & 0.411 & 0.254 & 0.115 & 0 \\
& & & & & $0 / 416$ & 0.386 & 0.362 & 0.339 & 0.319 & 0.302 & 0.287 \\
\hline \multirow{2}{*}{$1.2 \mathrm{~kg}$} & & & & & & & 0.96 & 0.77 & .0 .602 & 0.452 & 0.317 \\
& & & & & & & 0.407 & 0.384 & 0.363 & 0.344 & 0.327 \\
\hline
\end{tabular}

Table 6

\begin{tabular}{|c|c|c|c|c|c|c|c|c|c|c|c|}
\hline$X_{1} / Y_{1}$ & $\begin{array}{c}-1 \\
0.0025 \\
\end{array}$ & $\begin{array}{c}-0.8 \\
0.0027 \\
\end{array}$ & $\begin{array}{c}-0.6 \\
0.003 \\
\end{array}$ & $\begin{array}{c}-0.4 \\
0.0032 \\
\end{array}$ & $\begin{array}{c}-0.2 \\
0.0035 \\
\end{array}$ & $\begin{array}{c}0 \\
0.0037 \\
\end{array}$ & $\begin{array}{c}0.2 \\
0.004 \\
\end{array}$ & $\begin{array}{c}0.4 \\
0.0042 \\
\end{array}$ & $\begin{array}{c}0.6 \\
0.0045 \\
\end{array}$ & $\begin{array}{c}0.8 \\
0.0047 \\
\end{array}$ & $\begin{array}{c}1 \\
0.005 \\
\end{array}$ \\
\hline $0.9 \mathrm{~kg}$ & $\begin{array}{c}-0.63 \\
0.208\end{array}$ & $\begin{array}{c}-0.811 \\
0.186\end{array}$ & $\begin{array}{c}-0.973 \\
0.166\end{array}$ & 0 & & & & & & & \\
\hline $1.1 \mathrm{~kg}$ & $\begin{array}{c}0.232 \\
0.316\end{array}$ & $\begin{array}{c}0.0102 \\
0.288\end{array}$ & $\begin{array}{c}-0.191 \\
0.263\end{array}$ & $\begin{array}{r}-0.373 \\
0.241 \\
\end{array}$ & $\begin{array}{c}-0.539 \\
0.220\end{array}$ & $\begin{array}{c}-0.692 \\
0.200\end{array}$ & $\begin{array}{c}-0.962 \\
0.167\end{array}$ & $\begin{array}{c}-1 \\
0.15\end{array}$ & & & \\
\hline $1.3 \mathrm{~kg}$ & $\begin{array}{c}1 \\
0.4\end{array}$ & $\begin{array}{l}0.831 \\
0.391 \\
\end{array}$ & $\begin{array}{l}0.591 \\
0.361 \\
\end{array}$ & $\begin{array}{l}0.373 \\
0.334 \\
\end{array}$ & $\begin{array}{l}0.174 \\
0.310\end{array}$ & $\begin{array}{c}-0.008 \\
0.286\end{array}$ & $\begin{array}{c}-0.176 \\
0.265\end{array}$ & $\begin{array}{c}-0.331 \\
0.246 \\
\end{array}$ & $\begin{array}{r}-0.474 \\
0.228 \\
\end{array}$ & $\begin{array}{c}-0.607 \\
0.211\end{array}$ & $\begin{array}{c}-0.731 \\
0.196 \\
\end{array}$ \\
\hline $1.5 \mathrm{~kg}$ & & & & $\begin{array}{c}1 \\
0.4 \\
\end{array}$ & $\begin{array}{l}0.887 \\
0.398 \\
\end{array}$ & $\begin{array}{l}0.675 \\
0.372 \\
\end{array}$ & $\begin{array}{l}0.479 \\
0.347 \\
\end{array}$ & $\begin{array}{l}0.299 \\
0.325 \\
\end{array}$ & $\begin{array}{l}0.133 \\
0.304 \\
\end{array}$ & $\begin{array}{c}-0.022 \\
0.284 \\
\end{array}$ & $\begin{array}{c}-0.166 \\
0.267 \\
\end{array}$ \\
\hline $1.7 \mathrm{~kg}$ & & & & & & & & $\begin{array}{c}0.930 \\
0.4\end{array}$ & $\begin{array}{l}0.740 \\
0.280\end{array}$ & $\begin{array}{c}0.563 \\
0258\end{array}$ & $\begin{array}{l}0.399 \\
0.237\end{array}$ \\
\hline
\end{tabular}

$X_{3}=0\left(x_{3}=55^{0}\right)$

Table 7

$X_{3}=1\left(x_{3}=65^{0}\right)$

\begin{tabular}{|c|c|c|c|c|c|c|c|c|c|c|c|}
\hline$X_{1} / Y_{1}$ & -1 & -0.8 & -0.6 & -0.4 & -0.2 & 0 & 0.2 & 0.4 & 0.6 & 0.8 & 1 \\
& 0.0025 & 0.0027 & 0.003 & 0.0032 & 0.0035 & 0.0037 & 0.004 & 0.0042 & 0.0045 & 0.0047 & 0.005 \\
\hline \multirow{2}{*}{$1.45 \mathrm{~kg}$} & -0.421 & -0.633 & -0.843 & -0.1 & & & & & & & \\
& 0.234 & 0.208 & 0.182 & 0.265 & & & & & & \\
\\
\multirow{2}{*}{$1.6 \mathrm{~kg}$} & -0.210 & -0.005 & -0.218 & -0.430 & -0.639 & -0.846 & -0.1 & & & & \\
& 0.313 & 0.286 & 0.260 & 0.233 & 0.207 & 0.181 & 0.156 & & & \\
\hline \multirow{2}{*}{$1.8 \mathrm{~kg}$} & 1 & 0.832 & 0.614 & 0.398 & 0.185 & -0.025 & -0.234 & -0.441 & -0.646 & -0.849 & 0.1 \\
& 0.419 & 0.286 & 0.364 & 0.337 & 0.310 & 0.284 & 0.258 & 0.232 & 0.206 & 0.181 & 0.156 \\
\hline \multirow{2}{*}{$2 \mathrm{~kg}$} & & & & & 0.1 & 0.794 & 0.581 & 0.370 & 0.161 & -0.045 & \\
& & & & & 0.413 & 0.386 & 0.360 & 0.333 & 0.307 & 0.281 & \\
\hline \multirow{2}{*}{$2.2 \mathrm{~kg}$} & & & & & & & & & 0.969 & 0.758 & 0.550 \\
\end{tabular}


Because the models obtained are linear, it is sufficient to draw a conclusion based on the table data. Tables 3-5 show the masses of fiber contained in the values of the other two factors in the decomposed values of the third factor.

These conclusions can be drawn from the analysis of the computational results presented in the tables. It is found that the maximum mass of $1,2 \mathrm{~kg}$ in the table can be obtained from the last Eigen values of these factors.

The results of Table 6 show the highest mass extraction of $x_{3}$ at the values of the external factor, with the separation of $1,3 \mathrm{~kg}$ in all values of the other two factors, with the smallest mass $0,9 \mathrm{~kg}$ and the large mass $2,2 \mathrm{~kg} x_{1}$ and $x_{2}$ the initial minimum and final values of the factors respectively is coming.

\section{CONCLUSIONS}

1. Theoretically the thickness of the fibers on the surface of the seeds during the ginning was determined.

2. When the variable inclination angle $\alpha(\mathrm{rad})$ is $h=0.002 \mathrm{~m}$ with different values of $b_{0}$ angle of inclination $\varphi($ rad $)$ are obtained.

3. When the $\alpha$ (rad) the inclination angle of $T(H)$ tissue tension is $h=0.002 \mathrm{~m}$ different values of $b_{0}$ angle of inclination $\varphi$ (rad) are obtained.

4. Increasing the distance $b_{0}$ between the horizontal axis $h$, and the shaft and the vertical axis causes a sharp decrease in the angle of incision.

5 . With the increase in the distance $b_{0}$ between the vertical axis and the roller, there is a decrease in the in vertebral displacement angle.

6. It has been observed that increasing the distance between the rollers in the process of separating the fiber from the cotton seeds leads to a decrease in the tensile strength of the fiber.

\section{REFERENCES}

1. M. T. Khojiev, A. Juraev, O. Murodov, \& A. Rakhimov. (2019) Development of Design and Substantiation of the Parameters of the Separator for Fibrous Materials. In International Journal of Recent Technology and Engineering (IJRTE) (Issue 2).

2. A. Djuraev, J.Kh. Beknazarov, \& Sh.Sh. Kenjaboev. (2019) Development of an Effective Resource-Saving Design and Methods for Calculating the Parameters of Gears with Compound Wheels. In International Journal of Innovative Technology and Exploring Engineering (IJITEE) (Issue 1).

3. W. Stanley Anthony, C. Kenneth Bragg / Response of cotton fiber length distribution to production and ginning practices / Transactions of the Asae. 30 (1): 0290-0296 / 1987.

4. Anvar, J., \& Ozod, R. (2019). Analysis of the Interaction of Fibrous Material with a Multifaceted Grid of the Cleaner. In International Journal of Recent Technology and Engineering (IJRTE) (Issue 8).

5. N. Safarov. Mathematical model of cotton extraction from smooth cotton seeds. //International Journal of Advanced Research in Science, Engineering and Technology vol. 6, Issiue 11, November 2019 ISSN:2350-0328.

6. N.M. Safarov. Mathematical model for drying raw cotton in solar-dryer installations. //International Journal of Advanced Research in Science, Enjineering and Technology vol. 5, Issiue 9, September 2018 ISSN:2350-0328.

7. A. Djuraev, Sh. S. Khudaykulov, \& A. S. Jumaev. (2020). Development of the Design and Calculation of Parameters of the Saw Cylinder with an Elastic Bearing Support Jin. In International Journal of Recent Technology and Engineering (IJRTE) (Issue-5).
8. Djuraev A., Sh. Khudaykulov. Influence of saw cylinder parameters and support rigidity on vibration amplitude // International Journal of Advanced Research in Science, Engineering and Technology (Indiya). Vol. 6, Issue 9, September 2019. P.10702-10706.

9. Djuraev A., Sh. Khudaykulov. Analysis of the results of an experiment to determine the torque on the shaft of a gin saw cylinder // International Journal of Advanced Research in Science, Engineering and Technology (Indiya). Vol. 6, Issue 9, September 2019.P.10653-10653.

10. N. Safarov. Application of energy-saving texnological processes of gining cotton fiber.//Textile journal of Uzbekistan volume 4 nember1 quarter-4.

11. Djuraev A., Rajabov O.I Experimental study of the interaction of multifaceted and cylindrical spiky cylinder in cotton cleaner from small waste // International Journal of Advanced Research in Science, Engineering and Technology Vol. 6, Issue 3, March 2019 p.8376-8381. http://www.ijarset.com/volume-6-issue-3.html

12. Ozod Rajabov, Ziyodullo Shodiyev. Analysis of Small Fluctuations of a Multifaceted Mesh under the Influence of Technological Load from the Cleaned Cotton - Raw // International Journal of Advanced Research in Science, Engineering and Technology ISSN: 2350-0328 Vol. 6, Issue 10. October 2019.

\section{AUTHORS PROFILE}

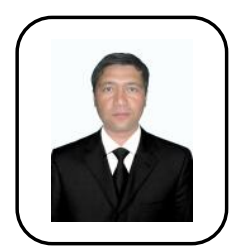

Abduvali Turgunpulatovich Majidov Doctoral student. Namangan Institute of Engineering and Technology. Email: niei_info@edu.uz, phone: +99893-4994693

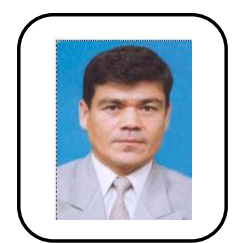

Nazirjon Muhammdjonovich Safarov candidate of technical science, dots. Namangan Institute of Engineering and Technology. Email: niei_info@edu.uz phone:+99894-5034800 